\title{
A matemática não é um monstro: jogos teatrais e matemática em um curso de extensão para professores
}

\author{
Vinicius Borovoy de Sant'ana ${ }^{1}$ \\ Maria Beatriz Dias da Silva Maia Porto²
}

\section{Resumo}

O trabalho ora apresentado traz um recorte da dissertação de Mestrado Profissional, realizado no Programa de Pós-graduação de Ensino em Educação Básica - Universidade do Estado do Rio de Janeiro, que articulou o teatro e a Educação Matemática a partir de um curso de extensão, denominado Dramatemática, produto educativo desenvolvido durante o curso, para professores dos Anos Iniciais atuantes em matemática. Para efetivação do trabalho, foi considerada a seguinte pergunta norteadora: qual matemática os professores dos anos iniciais desenvolvem a partir de jogos dramáticos e/ou teatrais? A fim de responder a esse questionamento foram desenvolvidas, em dez encontros, atividades de introdução à linguagem teatral e situações em que a matemática foi apresentada de forma colaborativa, crítica e contextualizada. Como objetivo principal, buscamos entender como os jogos dramáticos e/ou teatrais podem contribuir para a formação continuada dos professores de matemática do primeiro segmento do Ensino Fundamental. A pesquisa trata de uma investigação qualitativa e, para coleta de dados, foi realizada a observação dos participantes, registros contínuos, gravação dos encontros e avaliação final do curso. A avaliação final continha seis perguntas e, a partir das respostas, foram criadas três categorias. Para este trabalho ampliaremos a categoria "desmistificação da matemática (A matemática não é um monstro)", buscando entender o medo que, de certa forma, é histórico e cultural da matemática.

Palavras-chave: Formação de professores, Matemática nos anos iniciais, Teatro. Grupo colaborativo.

\section{Mathematics is not a monster: theater games and mathematics in an extension course for teachers}

\begin{abstract}
The work presented here presents an excerpt from the Professional Master's thesis, carried out in the Postgraduate Program of Teaching in Basic Education - State University of Rio de Janeiro, which articulated theater and Mathematics Education from an extension course, called Dramathematics, an educational product developed during the course, for teachers of the Early Years working in mathematics. In order to carry out the work, the following guiding question was considered: what mathematics do teachers in the early years develop from dramatic and / or theatrical games? In order to answer this question, activities were introduced in ten meetings to introduce the theatrical language and situations in which mathematics was presented in a collaborative, critical and contextualized way. As a main objective we seek to understand how dramatic and / or theatrical games can contribute to the continuing education of mathematics teachers in the first segment of elementary school. The research deals with a qualitative investigation and, for data collection, the observation of the participants, continuous records, recording of the meetings and final evaluation of the course were carried out. The final evaluation contained six questions and, based on the answers, three categories were created. For this work we will expand the category "Demystification of mathematics (Mathematics is not a monster)", seeking to understand the fear that, in a way, is historical and cultural in mathematics.
\end{abstract}

Keywords: teacher training, mathematics in the early years, theater, collaborative group.

\footnotetext{
1 Mestre em Ensino de Educação Básica, Secretaria de Estado de Educação de Minas Gerais, E-mail: viniciusborovoy@gmail.com.

${ }^{2}$ Doutora em Física, Universidade do Estado do Rio de Janeiro - Programa de Pós-graduação de Ensino em Educação Básica, E-mail: beatrizrj@gmail.com.
} 


\section{Introdução}

As primeiras demonstrações cognitivas relacionadas à matemática surgiram ainda no período Paleolítico. Essa primeira utilização está diretamente ligada às necessidades práticas impostas pelo convívio social (MIORIM, 1998). Inúmeras civilizações desenvolveram o seu próprio sistema numérico e a forma de contar. Dentre essas civilizações, destacamos os sumérios, os egípcios, os gregos, os chineses, os romanos, os maias, dentre outras. Essas civilizações, a partir da matemática por eles desenvolvida, contribuíram, de certa forma, para a atual conjuntura da mesma. Segundo D’Ambrosio, "todo conhecimento é resultado de um longo processo cumulativo de geração, de organização intelectual, de organização social e de difusão naturalmente não-dicotômicos entre si." (2009, p. 18).

A evolução da matemática aconteceu, e continua acontecendo, a partir das situações enfrentadas no cotidiano. Quando mencionamos problema, não estamos nos referindo à ausência de conhecimento, mas às circunstâncias corriqueiras com as quais diversos povos tiveram que lidar, e que, conforme eram resolvidas, os conhecimentos matemáticos se consolidavam. (ROQUE, 2013).

Sobre as questões que despertaram os interesses dos matemáticos, Roque comenta que:

podem ter sido de natureza cotidiana (contar, fazer contas); relativos à descrição dos fenômenos naturais (por que um corpo cai?; por que as estrelas se movem?); filosóficos (o que é conhecer?; como a matemática ajuda a alcançar o conhecimento verdadeiro?); ou, ainda, matemáticos (como legitimar certa técnica ou certo conceito?). (2013, p. 21).

O ensino de conhecimentos matemáticos foi estabelecido no período das antigas civilizações. Já naquela época, a matemática era considerada uma "ciência nobre" e era desenvolvida separadamente das "artes técnicas". (MIORIM, 1998). Essa segregação ocorria também com as pessoas que poderiam aprender os conteúdos matemáticos. Na época, apenas uma classe privilegiada contendo escribas, altos funcionários e dirigentes tinham acesso ao seu ensino, ou seja, a matemática, enquanto área de conhecimento, já estava "associada a uma classe privilegiada, já era considerada uma ciência nobre, desligada dos ofícios e das atividades manuais". (IBID).

Em meados do século XIX, a Educação Matemática surgiu como uma área das ciências sociais voltada para pesquisa da aprendizagem em ensino da matemática, que tem 
como objetivo principal buscar uma apresentação da matemática para o discente que seja mais significativa, tentando desmistificá-la.

A Educação Matemática se preocupa em “desenvolver uma prática docente adequada às necessidades da sociedade do século XXI". (SANT'ANA, 2019, p. 46). Dessa forma, diferentes abordagens são tratadas como tendências da Educação Matemática. Fiorentini (1995) aponta seis tendências: a formalista clássica, a empírico-ativista, a formalista moderna, a tecnicista e suas variações, a construtivista e a sócio-etnoculturalista, enquanto Sá (2016) nos traz novos eixos que compõe o atual campo de pesquisa em Educação Matemática. São eles: a Modelagem Matemática, a História da Matemática como recurso para o ensino, a Resolução de problemas, as Tecnologias e Matemática, a Educação Matemática Crítica, as Investigações Matemáticas em sala de aula, a Etnomatemática e a Matemática Lúdica ou Recreativa. Sobre essas tendências, não iremos evidenciar cada uma delas, pois foge à proposta desse trabalho, que é entender o "medo" que as pessoas trazem da matemática.

O histórico cultural e social de uma matemática para poucos, pode ter contribuído, de certa forma, para o medo que muitos têm dessa disciplina e que é o objeto desse trabalho. Outro aspecto que deve ser mencionado, e que também pode ter contribuído para esse medo, é a dissociação da matemática escolar da matemática cotidiana. Tal distanciamento tem sido alvo de investigação de diversos pesquisadores da área de Educação Matemática. De acordo com Zacarias:

\footnotetext{
Muitos educadores não perceberam que a Matemática escolar é apenas uma das muitas Matemáticas presentes no cotidiano e que, da maneira que está sendo ensinada, ela tem levado os alunos a perderem a sua capacidade crítica, tornando-os alienados, produzindo medo, submissão e exclusão (2008, p. 23).
}

O estigma de a matemática ser tida como uma disciplina maçante, inatingível e para poucos, costuma ser transmitido entre gerações. Não é raro de se ouvir pais dizendo para seus filhos que também tinham problemas com a matemática na escola e que a acham difícil. De acordo com Johson e Rising (1972, apud Vitti):

Muitas pessoas têm orgulho em manifestar ignorância em matemática. Poucos adultos admitem que foram fracos estudantes de história mas muitos pais de alunos enunciam o fato de que eles nunca entenderam matemática (1995, p. 25) 
O insucesso em determinadas matérias como história, geografia, ciências geralmente é atrelada à falta de atenção e de estudo do aluno. No entanto, se esse aluno for mal em matemática, ele provavelmente carregará o estigma de ter dificuldades para raciocinar.

Na busca por desmistificar todo o "medo" mencionado por muitos, da matemática, e ainda para trazê-la mais próxima ao cotidiano das pessoas, a pesquisa que deu origem ao trabalho ora apresentado foi desenvolvida com professores dos Anos iniciais de escolaridade, que ministram matemática e que não têm, necessariamente, formação na área.

Na realização do trabalho buscamos responder à pergunta diretriz: "qual matemática os professores dos Anos Iniciais desenvolvem a partir de jogos dramáticos e/ou teatrais?”. Propusemos então, como metodologia, a inserção de jogos teatrais e/ou dramáticos ${ }^{1}$ para o ensino de matemática.

A utilização de jogos dramáticos e de jogos teatrais, quando utilizados como metodologia para ensino da matemática, pode ser inserida nas seguintes tendências da Educação Matemática: Etnomatemática e Matemática Lúdica. A primeira dessas tendências, "é a matemática praticada por grupos culturais, tais como comunidades urbanas e rurais, classes profissionais, crianças de uma certa faixa etária [...] e tantos outros grupos que se identificam por objetivos e tradições comuns aos grupos." (D’AMBROSIO, 2011, p. 9). A Etnomatemática está diretamente ligada com o "fazer matemático" do dia a dia. Dessa forma, ao tratarmos com atividades que envolvam cenas com situações matemáticas sejam de compra, de venda, de quantificação, de comparação, de medição, estamos abordando, na prática, a Etnomatemática. Em relação à matemática lúdica, essa geralmente é associada aos jogos e à utilização de recursos como: vídeos, música, curiosidades, softwares, animações, teatro, entre outros. Os jogos teatrais são capazes de proporcionar essa ludicidade e imaginação.

Nesse trabalho, a inserção dos jogos dramáticos e/ou teatrais na matemática foi estabelecida a partir de um curso de extensão intitulado Dramatemática, produto educacional desenvolvido no curso de Mestrado Profissional do Programa de Pós-graduação de Ensino em Educação Básica, PPGEB, da Universidade do Estado do Rio de Janeiro.

\footnotetext{
${ }^{1}$ Essa diferenciação é feita, pois os jogos teatrais são atividades que devem obrigatoriamente ser apresentada para uma plateia. Enquanto os jogos dramáticos, são atividades de desenvolvimento do ator.
} 
Polyphonía, v. 32/2, jul./dez. 2021210

O Dramatemática foi cenário de trocas e experiências para a coleta de dados da pesquisa, na busca pela resposta à pergunta norteadora já mencionada. O curso englobou trinta e duas atividades criadas e/ou adaptadas a partir daquelas propostas por Viola Spolin (2005, 2008). A maior importância dessas atividades era proporcionar uma experiência diferente para os professores no processo de ensino da matemática. Desta forma, "o Teatro se torna um instrumento de materialização da narrativa onde abstrações de conceitos, valores e ideias contidos na trama tomam vida no espetáculo teatral, de forma que parecem reais". (POLIGICCHIO, 2011, p. 80).

Além da dissertação desenvolvida e do próprio curso Dramatemática, também foram elaborados dois artefatos educacionais:

- Curso de Extensão Dramatemática: Sequência Didática (SANT’ANA; PORTO, 2019a).

- Curso de Extensão Dramatemática: Diário, aplicações e experiência aula a aula (SANT'ANA; PORTO, 2019b).

O primeiro deles apresenta a metodologia realizada durante as dez aulas ministradas no Dramatemática, enquanto o segundo demonstra de forma detalhada como as atividades foram aplicadas, as reações, as sugestões e os comentários dos participantes.

Deve ser ressaltado que as atividades aplicadas ao longo dos dez encontros do Dramatemática, não seguiram um ano de escolaridade específico, são replicáveis, e podem ser aplicadas para toda a Educação Básica.

\section{Curso de Extensão Dramatemática}

O curso de Extensão Dramatemática aconteceu no segundo semestre de 2018, voltado para docentes que atuam no primeiro segmento do ensino fundamental, graduados em pedagogia, matemática e/ou na escola normal. O Dramatemática teve início com quinze participantes, dos quais doze terminaram o curso, tendo realizado todas as atividades e preenchido o questionário final.

O desenvolvimento e a realização do curso englobaram: gravação em áudio de todos os encontros, registros fotográficos, relatórios e avaliação, por meio de questionários, realizados pelos participantes que concluíram o processo. 
Foram aplicadas, conforme já mencionado, trinta e duas atividades criadas ou adaptadas em dez encontros que levaram um pouco mais de três meses de curso. Os encontros ocorriam na Universidade do Estado do Rio de Janeiro (UERJ), sempre aos sábados, das 9h às $12 \mathrm{~h}$.

Cada aula tinha a seguinte estrutura básica: conversa inicial, alongamento corporal e vocal, realização de jogos dramáticos e/ou teatrais e conversa final.

Ao longo do processo, as atividades elaboradas abordaram os seguintes conteúdos matemáticos: múltiplos, divisores, paridade, diagrama de Venn, figuras geométricas, as operações fundamentais, sequência numérica e raciocínio lógico. Uma vez que a abordagem do ensino da matemática foi realizada através de jogos teatrais, além dos conteúdos acadêmicos, importantes competências puderam ser trabalhadas e desenvolvidas. Dentre essas competências, destacamos: a memorização, o foco, os desenvolvimentos corporal e espacial, o trabalho em equipe, a escuta, o diálogo e o respeito.

Ao final do curso, foi aplicado um questionário para os doze participantes concluintes, cujas seis questões nele contidas, estão a seguir:

1. Relate um pouco sobre a sua formação acadêmica e a sua experiência profissional;

2. Cite três pontos positivos do curso e três pontos que possam ser melhorados;

3. Comente um pouco sobre a realização do curso, se teve utilidade para a sua prática docente;

4. Em relação às atividades aplicadas ao longo do curso, você utilizou alguma delas? Se sim, comente a respeito. Aponte a atividade realizada, a série em que foi aplicada e relate como foi o retorno dos alunos.

5. Quais foram as principais contribuições do curso para a sua vida profissional e pessoal?

6. Essa pergunta é livre, escrevam aqui suas opiniões, sugestões e críticas para o andamento do curso “Dramatemática”. (SANT’ANA, 2019)

As respostas fornecidas pelos participantes às questões contidas nos formulários de avaliação permitiram que fossem elaboradas categorias para análise dos resultados. De acordo com o pensamento de Bardin, a categorização é realizada através da: 


\begin{abstract}
classificação de elementos constitutivos de um conjunto, por diferenciação e, seguidamente, por reagrupamento segundo o gênero (analogia), com os critérios previamente definidos. As categorias, são rubricas ou classes, as quais reúnem um grupo de elementos ... sob um título genérico, agrupamento esse efetuado em razão dos caracteres comuns destes elementos (BARDIN, 2006, p. 117)
\end{abstract}

De posse das respostas dos participantes, foram elaboradas as três categorias a seguir:

- Contribuição para formação continuada a partir das atividades troca de saberes, experiências e interações do grupo;

- Aplicabilidade e a contextualização a partir dos jogos dramáticos e/ou teatrais;

- Desmistificação da matemática (a matemática não é um monstro).

Para o desenvolvimento deste trabalho, nos debruçaremos sobre a terceira categoria: “Desmistificação da matemática (a matemática não é um monstro)".

\title{
Desmistificação da matemática (a matemática não é um monstro)
}

Para estabelecermos a relação do teatro com a matemática e, consequentemente, termos dados para a elaboração da categoria "Desmistificação da matemática (a matemática não é um monstro), foram utilizados os autores: Ubiratan D’Ambrosio (1996), Beatriz D’Ambrosio e Celi Lopes (2015), Vygotsky (1998), Ole Skovsmose (2013) e Viola Spolin (2008).

Esses autores foram fundamentais para toda a elaboração do Dramatemática e do entendimento da matemática enquanto uma disciplina libertadora e crítica. No entanto, ao optarmos para o desdobramento da pesquisa ora intitulada "a matemática não é um monstro", utilizaremos os autores: Vitti (1995), Lins (2004), Cohen (2000) e Carraher (2011) por tratarem de medo, fracasso escolar e do monstro criado para a matemática.

Conforme apresentado na introdução, a matemática traz um histórico de segregação e elitismo muito grande. Até hoje é comum ouvirmos que "se a pessoa é boa em matemática ela é um crânio", como se o conhecimento de alguém fosse reduzido apenas por saber ou não matemática.

Entendemos que quando abordamos o que estamos chamando de "o medo da matemática", um ponto que não pode deixar de ser mencionado é o fracasso escolar. O medo mencionado, muitas vezes é consequência de "técnicas de ensino inadequadas ou falta de domínio da técnica correta pelo professor.” (ANGELUCCI et al, 2004, p. 61). Ao ministrar 
qualquer disciplina, não apenas a matemática, se o docente não domina o conteúdo, este, invariavelmente, acaba sendo menosprezado e ensinado de forma confusa para os estudantes. Este fato acarreta, muitas vezes, na dificuldade de entendimento por parte dos alunos e em retenções.

Dessa forma, Vitti (1995, p. 39) ressalta que "o medo que os alunos têm em relação à matemática, o baixo rendimento obtido devido à falta de compreensão e o preconceito que existe em torno da matemática são provocados, na maioria das vezes, pelo próprio professor".

Portando, metodologias de ensino que dialoguem com os eixos de pesquisa da Educação Matemática podem propiciar uma proximidade dos alunos com a matemática e desmistificar esse medo.

\section{Matemática e o fracasso escolar}

Segundo Carraher (2011), para tentar explicar o fracasso escolar, inúmeros culpados têm sido sugeridos:

[...] o aluno, que não tem capacidade; o professor, que é mal preparado; as secretarias de educação, que não remuneram seus professores; as universidades, que não formam bem o professor; o estudante universitário, que não aprendeu no secundário o que deveria ter aprendido e agora não consegue aprender o que seus professores universitários lhe ensinam (2011, p. 37).

De fato, todas essas situações dificultam a atividade de ensinar a matemática, porém, não podem ser atribuídas como os motivadores para o fracasso da disciplina. A maioria dos itens anteriores podem ser recuperados. O distanciamento da formação universitária da prática de sala de aula é um problema, porém, atualmente, existem inúmeros cursos de formação continuada capazes de proporcionar ao educador novas formas de ensino (COLLINS, 2018). Entendemos que a maioria dos professores formados possuem domínio dos conteúdos da matemática escolar, porém, muitas vezes, falta a eles, a arte de ensinar de forma mais atrativa, divertida e significativa.

Então, o importante é que "os educadores, todos nós, precisamos não encontrar os culpados, mas encontrar as formas eficientes de ensino e aprendizagem em nossa sociedade". (CARRAHER, 2011, p. 37) 
Ainda sobre o fracasso escolar, Vitti (1995) também aponta as más condições do trabalho do professor, o salário, a falta de preparo em sua formação, as condições de estudo do aluno entre outros itens. No entanto, esses elementos seriam causadores do fracasso de qualquer disciplina, e não exclusivamente da matemática.

Para Vitti (1995), além das questões metodológicas, o fracasso da matemática se deve a diversos fatores:

\begin{abstract}
Desde o fato da escola não valorizar o que o aluno já traz consigo de habilidades em matemática; por que e como começam a surgir na escola as dificuldades na assimilação da matemática [...] o estigma que a matemática carrega de ser considerada difícil, abstrata, a que muitos julgam não ter acesso, a ponto de sentirem orgulho em manifestar ignorância em matemática; como a aprendizagem da matemática represente um critério avaliador da inteligência[...] o ensino divorciado das aplicações; o constante uso do livro didático que apresenta teorias incompletas e desvinculadas de aplicações (1995, p. 37-38).
\end{abstract}

Falta ao educador proporcionar o protagonismo para os discentes e isso independe da disciplina. Estabelecer diálogo, proporcionar atividades em grupo, elaborar atividades com temas atuais e coerentes, ouvir os alunos, são algumas atitudes importantes para o educador do século XXI.

Estabelecida a situação do fracasso escolar, vamos retratar sobre o medo da matemática a ponto de compará-la com um monstro.

\title{
Matemática e a criação de monstros
}

O distanciamento da matemática escolar da matemática do cotidiano pode contribuir para o medo e, consequentemente, para a criação de monstros.

Para Lins (2004), ao estudar português na escola você acaba o colocando em prática ao falar, ler, escrever, tendo um contato em diversas situações. Com relação à matemática, uma solução que Lins (2004) aponta:

é buscar fazer os alunos verem "a Matemática na vida real", "trazer a vida real para as aulas de Matemática". Certas ideias da Etnomatemática, como propostas por Ubiratan D' Ambrósio, a Matemática realista da equipe do Instituto Freudenthal (Utrecht, Holanda), e a Modelagem Matemática como recurso pedagógico, todas estas e outras propostas têm por objetivo - ao menos em parte -ligar a Matemática que se estuda nas salas de aula com a "Matemática do cotidiano", "da vida" (2004, p. 93). 
Em seu trabalho, Lins (2004) aborda a matemática do matemático e a matemática de rua. Para o autor, a matemática do matemático é "resultado de um esforço (processo histórico) de colar significados a significantes." (2004, p. 95). Se um matemático define, por exemplo, que ""limite de uma função f é tal e tal e tal", é isso que "limite de uma função f" fica sendo, e isso não se dá por alguma causa natural (definição descritiva), mas por uma determinação simbólica (definição constitutiva).” (IBID, p. 95).

Ou seja, se um matemático estabelece um objeto, não cabe discutir se esta definição “corresponde bem ou não a algo fora da própria Matemática." (IBID, p. 95). É justamente nessa única matemática que pode estar o problema para os baixos rendimentos. A maioria dos professores não se preocupam com o desenvolvimento deste aluno, no pensar do porquê ele ter errado em determinado momento. Muitos professores só se preocupam com o resultado e a matemática acaba se limitando a uma única resolução correta.

O distanciamento dos conhecimentos dos Matemáticos da realidade dos alunos é que pode tornar a matemática algo "sobrenatural” que, segundo Lins (2004, p. 100), “o internalismo coloca o matemático na posição de um deus. Fiat lux. Falou, está falado".

Todos esses símbolos matemáticos, conjuntos numéricos, equações, funções, teoremas, axiomas, surgem como "monstros" para os discentes que não são capazes de identificar esses conteúdos para situações cotidianas. É justamente dessa ausência de associação da matemática com o dia a dia, que vão surgindo os "monstros". (Lins, 2004)

Para Lins (2004), ao pensarmos na ideia de monstros, a reação é de paralização, pois não sabemos como devemos agir ao nos depararmos com eles. Para compreendermos o significado desses monstros para nós e para nossa cultura, nos apoiaremos no trabalho de Jeffrey Jerome Cohen (2000), A Cultura dos Monstros: Sete Teses.

Em seu trabalho, Cohen (2000), aborda sete teses que buscam entender as culturas através dos monstros que elas produzem. Não iremos abordar todas as sete teses, nos preocuparemos em destacar as relações de "monstro" que mais se adequam ao medo da matemática. Dessa forma, escolhemos a primeira, a segunda e a sexta teses apresentadas no trabalho, pois estão relacionadas com o encontrar com monstro, o deixar escapar (comodismo) e a valorização desse monstro (matemática como disciplina superior).

A primeira das teses, intitulada "o corpo de monstro é um corpo Cultural”, retrata justamente o monstro como algo que não saberíamos enfrentar. Lins (2004), em seu texto, 
utiliza o trabalho de Cohen (2000) e comenta sobre o "se deparar com um vampiro". Como faria para enfrentá-lo? Força bruta, armas convencionais, balas de prata. Enfim não saberíamos o que fazer porque não fomos condicionados para tal situação. Essa corporificação do monstro nos remete ao sofrimento prévio dos alunos, quando nos perguntam como é determinada matéria que eles ainda não viram. Ou seja, eles nem têm conhecimento do assunto e já criam barreiras, provavelmente, por terem escutado de amigos mais velhos que determinado assunto é difícil.

Na segunda tese, "O monstro sempre escapa", Lins (2004) comenta que é comum deixarmos esse monstro escapar para mantermos a nossa rotina. Trazendo para a realidade do professor, Lins (2004, p. 106) relata que "é mais fácil dar aula expositiva e manter os monstros no limbo".

Na sexta tese, "O medo do monstro é realmente uma espécie de desejo", Lins (2004, p. 110) ressalta que "se a Matemática fosse coisa só para os inteligentes, mas ao mesmo tempo fôssemos todos "inteligentes" não haveria capital acumulado, não haveria desejo", ou seja, é bem provável que se a matemática não ganhasse tanta notoriedade por esse medo, ela não teria tanto peso em avaliações, concursos, vestibulares e na carga horária escolar.

De uma maneira geral, o trabalho de Lins (2004) traz a importância da matemática de o matemático tornar uma matemática escolar acessível e, consequentemente, ser aplicável ao que ele chama de matemática de rua. Lins (2004) espera que:

uma Educação Matemática faça o monstro monstruoso tornar-se monstro de estimação, este não seria um feito menor, mesmo que fosse para o aluno dizer "sei que é isso e não me assusta, mas não quero" (2004, p. 118).

A citação anterior deixa evidente que o estudante tem muitas possibilidades, podendo seguir a área que desejar, mas, no entanto, é algo lamentável quando encontramos alunos que optam por carreiras que acreditam não ter matemática em suas grades curriculares, apenas para evitar o monstro.

Mediante todo o exposto, acreditamos que o teatro, assim como os novos eixos da Educação Matemática, pode contribuir para uma melhor experiência com a matemática escolar, pois "[... entendemos que essa brincadeira educativa é importante para a identificação 
do aluno com a escola, tornando-a um dos seus ambientes preferidos". (SANT'ANA, 2019, p. 100).

Se o ensino e o desenvolvimento da matemática fossem aplicados nas necessidades e realidade do homem e em seu momento histórico, o ensino desta disciplina seria "de uma maneira mais clara e significativa para o aluno, além do que proporcionaria motivação nas aulas, tranqüilidade na avaliação, e momentos de prazer”. (VITTI, 1995, p 40). Esses momentos de um ensino mais leve e atrativo podem diminuir esse "monstro" criado acerca da matemática.

\section{Resultados e Discussões}

\section{Dramatemática e os monstros}

Acreditamos que as trinta e duas atividades aplicadas no curso Dramatemática tenham servido como uma experimentação de uma matemática mais prática, colaborativa, mais assistemática e mais humana. Entendemos que a leveza que o teatro proporciona a partir dos jogos teatrais e/ou dramáticos, estabelece um "fazer matemático" capaz de diminuir o medo da matemática e, consequentemente, a associação aos monstros.

Para Spolin as oficinas de jogos teatrais

[...] são úteis ao desenvolver a habilidade dos alunos em comunicar-se por meio do discurso e da escrita, e de formas não verbais. São fontes de energia que ajudam os alunos a aprimorar habilidades de concentração, resolução de problemas e interação em grupo (2008, p. 29).

Destacaremos aqui algumas atividades que foram realizadas durante o curso. No primeiro encontro pretendíamos conhecer um pouco mais da relação deles com a matemática. Então, em roda, pedimos que falassem o que a matemática representava para eles. Dentre os quatorze participantes presentes, oito eram pedagogos e seis eram matemáticos.

Entre os oito participantes pedagogos surgiram as seguintes palavras: cálculo, fogo, dificuldade, drama, números, exercícios, divisão e observação. Já os seis participantes matemáticos trouxeram as seguintes palavras: operação, raciocínio, fração, problematização, música e diversão. Essas palavras evidenciaram que os pedagogos têm, de modo geral, uma relação mais distante com a matemática. As expressões "dificuldade" e "drama” revelam um 
certo problema com a disciplina. Essa dificuldade com a matemática é apresentada por Curi (2004) ao relatar que na formação em pedagogia, a carga horária destinada à matemática é de aproximadamente $4 \%$ a $5 \%$ da carga horária total dos cursos levantados em sua pesquisa. Segundo Curi (2004, p. 76-77),

É possível considerar que os futuros professores concluem cursos de formação sem conhecimentos de conteúdos matemáticos com os quais irão trabalhar, tanto no que concerne a conceitos quanto a procedimentos, como também da própria linguagem matemática que utilizarão em sua prática docente. Em outras palavras, parece haver uma concepção de que o professor polivalente não precisa 'saber Matemática' e que basta saber como ensiná-la.

Para concretizar a simbologia da matemática para os participantes, pedimos que desenhassem o que seria a matemática para eles. Escolhemos o desenho, pois ele "faz parte do desenvolvimento de qualquer ser humano, independentemente de sua idade e, portanto, não deixa de ser mais ou menos importante no desenvolvimento psicofísico de uma criança." (POSSA; VARGAS, 2014, p. 1). Segundo os mesmos autores, “o desenho, como linguagem artística, proporciona à criança oportunidades que possibilitam com que ela expresse aqui e agora seus sentimentos a respeito de algo. E em alguns casos, até mesmo mostrar suas angústias e seus medos.” (POSSA; VARGAS, 2014, p. 2).

Dentre os quatorze desenhos, destacaremos um por representar nitidamente a questão do medo pela disciplina.

Fig 1. Representação da matemática para um participante do Dramatemática

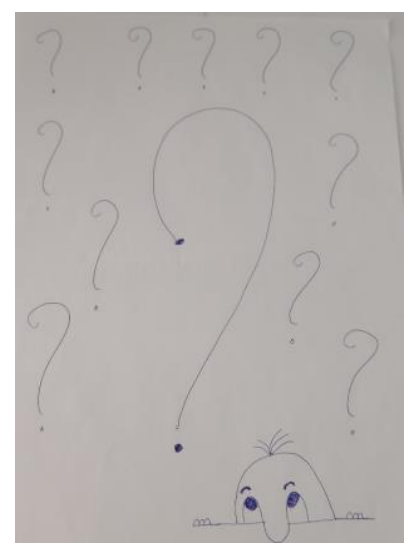

Fonte: (Sant'ana e Porto, 2019b). 
$\mathrm{Na}$ figura anterior fica evidente que existe uma dúvida, muito provavelmente a respeito de conteúdo. A figura do aluno olhando de maneira desconfiada, também nos remete ao mito da matemática.

Seguindo com as atividades, foram aplicados alguns "caminhar pelo espaço", atividade comum ao desenvolvimento do ator, que explora a percepção corporal e espacial do participante.

O corpo é instrumento fundamental para o teatro, pois requer a "vivência do momento, em sua presença expressiva, materializando no corpo os pensamentos, as reflexões, as sensações e os sentimentos". (PEDROSO, 2007, p. 3).

Assim, na atividade caminhar pelo espaço 1 (Sant'ana e Porto, 2019a) foi proposto aos participantes que caminhassem seguindo quatro níveis de velocidade: o nível 4 seria o mais rápido, o nível 3 se adequava ao passo normal do participante, o nível 2 seria um pouco mais lento e o nível 1, mais lento ainda. Junto a essas diferentes velocidades, exploramos diferentes planos: alto, médio e baixo.

$\mathrm{Na}$ atividade caminhar pelo espaço 3 (Ibid), os participantes caminhavam explorando o espaço e, ao comando do mediador, realizaram diferentes agrupamentos. Por exemplo, formar grupos de 3 pessoas, 4 pessoas, etc.

O caminhar pelo espaço 4 (Ibid) tem como proposta que os participantes caminhassem pelo espaço de tal forma que, quando o mediador falasse um número PAR, eles deveriam parar, quando o mediador falasse um número ímpar, os participantes deveriam continuar a caminhada. Com essa atividade conseguimos abordar a paridade dos números.

No caminhar pelo espaço 7 (Ibid), os participantes deveriam caminhar pelo espaço e ao comando do mediador (com palmas), deveriam formar diferentes figuras geométricas utilizando apenas o seu corpo.

Uma atividade bastante replicada pelos participantes foi a contar até 10 (Ibid). Nessa atividade, um aluno inicia a sequência e cada aluno da roda, não necessariamente na ordem que estão posicionados, acrescenta um número. Se dois ou mais alunos falam juntos, a sequência recomeça. Apenas com o olhar sobre a roda, cada participante deveria perceber se pode falar ou não. O aluno deveria seguir a sequência com rapidez evitando deixar "buracos".

Como já mencionado, ao final de cada aula, tínhamos uma conversa sobre as atividades, as possíveis adaptações e aplicabilidade da mesma. Ao final do encontro, 
entregávamos dois cadernos para dois diferentes participantes e eles deveriam relatar o que tinham achado da aula. Após reunirmos os relatos nos cadernos e as respostas dos questionários, percebemos que onze dos doze concluintes replicaram pelo menos uma atividade.

As respostas às questões contidas nos formulários foram agrupadas em três categorias, já mencionadas, sendo uma delas a desmistificação da matemática (a matemática não é um monstro). Dessa forma, como análise dos resultados, abordaremos especificamente as respostas que foram localizadas nessa categoria.

\section{Análise dos trechos}

Mediante as respostas dos formulários, elaboramos um quadro contendo trechos onde a passagem pela desmistificação da matemática fica clara. No quadro consta o participante, a menção a uma das questões listadas na seção: Curso de Extensão Dramatemática, e a resposta na qual se encontra o trecho. Esclarecemos que, por questões de privacidade, nomeamos os participantes como "P1", "P2", seguindo a ordem alfabética dos nomes deles.

\section{Quadro 1. Trechos que comprovam a desmistificação da matemática}

\begin{tabular}{|c|c|}
\hline Participante & Questão \\
\hline $\mathrm{P} 1$ & 2 \\
\hline \multicolumn{2}{|c|}{$\begin{array}{l}\text { "Tirou a ideia de que a matemática não é a vilã, que pode ser trabalhada de forma lúdica e interativa, } \\
\text { despertando nos alunos o interesse por vários assuntos." }\end{array}$} \\
\hline P3 & 5 \\
\hline \multicolumn{2}{|c|}{$\begin{array}{l}\text { "Visualizar a Matemática de forma diferente, o que me fez entender que não é preciso temê-la, mas sim que é } \\
\text { possível perceber formas prazerosas de ensiná-la aos alunos." }\end{array}$} \\
\hline P5 & 5 \\
\hline \multicolumn{2}{|c|}{ "[...] Ratificação de que a matemática pode ser ensinada de forma lúdica e prazerosa." } \\
\hline P6 & 5 \\
\hline \multicolumn{2}{|c|}{$\begin{array}{l}\text { "O curso me fez ver que a matemática pode ser vista de forma humana, não apenas como metódica e exata. } \\
\text { Amadureci muito, passei a ter como objetivo ensinar de forma prazerosa, menos formal. É fundamental } \\
\text { quebrar essa imagem negativa criada por um ensino tradicional e por uma cultura egoísta de elitização da } \\
\text { matemática." }\end{array}$} \\
\hline $\mathrm{P}^{2}$ & Linha 43 \\
\hline \multicolumn{2}{|c|}{$\begin{array}{l}\text { "A Matemática pode e deve ser mais leve e prazerosa que no tempo em que aprendi. Ela faz parte do tempo } \\
\text { em que o lúdico deve fazer parte no processo de ensino e aprendizagem, tornando esse processo mais valioso } \\
\text { e significativo." }\end{array}$} \\
\hline P9 & Linha 46 \\
\hline
\end{tabular}

${ }^{2} \mathrm{O}$ participante P9 respondeu às perguntas em um único texto. Então, indicamos a linha presente em cada trecho. 
"Como tentei demonstrar anteriormente, o curso é de muita valia, principalmente para desmistificar a ideia de uma disciplina conceitual e lógica. É possível tornar o aprendizado de Matemática muito mais leve e divertido."

\begin{tabular}{l|r} 
P12 & 3 \\
\hline
\end{tabular}

"Como uma participante disse em uma das aulas, matemática sempre foi um monstro para mim. E escolho sempre fazer atividades que envolvam essa disciplina, o curso me deu um leque maior de possibilidades para quebrar meus próprios paradigmas e desenvolver uma aula mais dinâmica."

Fonte: (Sant'ana, 2019).

Como foi visto, a maioria dos cursistas têm grande dificuldade com o ensino da Matemática, fato que pode gerar medo pela disciplina. Para Sanchez (2004), essas dificuldades podem se manifestar nos seguintes aspectos:

Dificuldades em relação ao desenvolvimento cognitivo e à construção da experiência matemática; do tipo da conquista de noções básicas e princípios numéricos, da conquista da numeração, quanto à prática das operações básicas, quanto à mecânica ou quanto à compreensão do significado das operações. Dificuldades na resolução de problemas, o que implica a compreensão do problema, compreensão e habilidade para analisar o problema e raciocinar matematicamente. Dificuldades quanto às crenças, às atitudes, às expectativas e aos fatores emocionais acerca da matemática. Questões de grande interesse e que com o tempo podem dar lugar ao fenômeno da ansiedade para com a matemática e que sintetiza o acúmulo de problemas que os alunos maiores experimentam diante do contato com a matemática. Dificuldades relativas à própria complexidade da matemática, como seu alto nível de abstração e generalização, a complexidade dos conceitos e algoritmos. [...] Dificuldades originadas no ensino inadequado ou insuficiente, seja porque à organização do mesmo não está bem sequenciado, ou não se proporcionam elementos de motivação suficientes; seja porque os conteúdos não se ajustam às necessidades e ao nível de desenvolvimento do aluno, ou não estão adequados ao nível de abstração, ou não se treinam as habilidades prévias; seja porque a metodologia é muito pouco motivadora e muito pouco eficaz (SANCHEZ, 2004, p. 174).

São muitas as dificuldades e, para a pesquisa, não tínhamos interesse em entender qual dificuldade gerou o medo pela disciplina, e sim proporcionar uma articulação com o teatro e a matemática. No entanto, com os trechos destacados, nos foi apontado que a visão da matemática como uma vilã foi desmistificada através das atividades do Dramatemática. Portanto, a utilização dos jogos teatrais e/ou dramáticos:

"podem se tornar meio facilitador no aprendizado das demais disciplinas, já que contribui para a melhora no raciocínio, na vivência de novas experiências, como meio facilitador do processo ensino-aprendizagem, uma vez que trabalha com respostas a estímulos imediatos" (FABI, 2013, p. 5). 
As atividades aqui apresentadas foram algumas das trinta e duas aplicadas ao longo do curso e essa forma mais leve, criativa, participativa e dinâmica, através das atividades teatrais e, que contribuiu pelo menos naquele momento para uma quebra de paradigma sobre o ensino da matemática e para motivar os professores, principalmente os que tinham medo da disciplina, a se aprofundar e aplicar mais atividades lúdicas em suas salas de aula.

Assim, é atribuído ao teatro ser "uma ferramenta útil, certamente não a única - e nem temos a pretensão de apresentá-la como a melhor -, mas um veículo eficiente para capacitar os alunos ao mundo da imaginação, da ultrapassagem da realidade, das abstrações”. (POLIGICCHIO, 2011, p. 12)

\section{Conclusões}

Ao final de mais de três meses de curso, o retorno dos participantes do curso foi positivo. A partir das respostas, principalmente dos trechos destacados, acreditamos que o Medo da matemática foi suprido ou pelo menos diminuído.

Acreditamos ter atingido a pergunta diretriz que foi "qual matemática os professores dos Anos Iniciais desenvolvem a partir de jogos dramáticos e/ou teatrais?”, pois ao longo de todo o curso, mesmo sem seguir uma série específica, conseguimos abordar diversos conteúdos da matemática, por meio das atividades teatrais e de forma leve, divertida, colaborativa e sem se preocupar com certo e errado. Essa leveza ao ensinar e abordar conteúdos da matemática pode ajudar a diminuir esse medo e consequentemente o fracasso da disciplina.

Temos a expectativa de que as atividades do Dramatemática sejam capazes de suavizar as aulas de matemática. Não apontamos o teatro como solução para ensino da matemática, porém é um facilitador para a abstração que a matemática exige e pode ser um recurso mais dinâmico para diminuir e/ou acabar com esse medo da matemática.

O mais importante é que tenhamos uma gama de conhecimentos, recursos e atividades que tornem a nossa sala de aula mais atrativa e colaborativa. A área da Educação Matemática juntamente com a Sociedade Brasileira de Educação Matemática (SBEM) propicia esses estudos, através de artigos, relatos e oficinas nessa temática.

E por fim, esperamos que a dissertação e os produtos didático-pedagógicos associados sejam um ponto de partida para muitas pesquisas e que surjam mais Dramatemáticas. 


\section{Referências}

ANGELUCCI, C. B; KALMUS, J; PAPARELLI, R; PATTO, M. H. S. O estado da arte da pesquisa sobre o fracasso escolar (1991-2002): um estudo introdutório. Educação e Pesquisa, São Paulo, v. 30, n. 1, p. 51-72, 2004.

BARDIN, L. Análise de conteúdo. Lisboa: Edições 70, 2006.

BICUDO, M. A. V.; GARNICA, A. V. M. Filosofia da Educação Matemática. 4 ed. Belo Horizonte: Autêntica, 2011.

CARRAHER, T. N. Na vida dez, na escola zero.16 ed. São Paulo: Cortez, 2011.

COLLINS, R. Artigo debate formação de professores de matemática. Disponível em: https://impa.br/noticias/artigo-debate-formacao-de-professores-de-matematica/. Acesso em 09 de agosto de 2020.

COHEN, J. J. A cultura dos monstros: sete teses. In DA SILVA, T. T. (Org) Pedagogia dos Monstros. Belo Horizonte: Autêntica, 2000, p. 22-60.

CURI, E. Formação de professores polivalentes: uma análise do conhecimento para ensinar Matemática e de crenças e atitudes que interferem na constituição desses conhecimentos. 2004. Tese (Doutorado em Educação Matemática) - Pontifícia Universidade Católica de São Paulo, São Paulo, 2001.

D'AMBROSIO, B. S.; LOPES, C. E. Insubordinação Criativa: um convite à reinvenção do educador matemático. Bolema, Rio Claro, SP, v. 29, n. 51, p. 1-17, abr. 2015. Disponível em: http://www.scielo.br/pdf/bolema/v29n51/1980-4415-bolema-29-51-0001.pdf. Acesso em: $02 / 08 / 2020$.

D'AMBROSIO, U. Educação matemática: da teoria à prática.17. ed. Campinas: Papirus, 2009.

Educação Matemática: da teoria à prática. Campinas: Papirus, 1996.

Etnomatemática: elo entre as tradições e a modernidade. Belo Horizonte: Autêntica Editora, 2011.

FABI, M. C. Os Jogos Teatrais e as possibilidades de ação e interação com e entre estudantes de ensino médio de escola pública integral. Especialização em Educação integral. Universidade Federal de Santa Catarina. Disponível em https://repositorio.ufsc.br/bitstream/handle/123456789/105655/MARIA\%20CRISTINA\%20FABI.pdf?sequence=1\&is Allowed=y. Acessoem 23 abr. 2021.

FIORENTINI, D. Alguns modos de ver e conceber o ensino da matemática no Brasil. Zetetiké, Campinas, v. 3, n. 4, p. 1-37, nov. 1995. 
LINS, R. C. Matemática, Monstros, Significados e Educação Matemática. In BICUDO, M. A. V; BORBA, M. de C. (Orgs). Educação Matemática pesquisa em movimento. São Paulo: Editora Cortez, 2004, p. 93-120.

MIORIM, M. A. Introdução à História da educação matemática. São Paulo: Atual, 1998.

PEDROSO, J. C. A percepção do corpo cênico em Klauss Vianna e Merleau-Ponty. In: Reunião científica de pesquisa e pós-graduação em artes cênicas, 4, 2007, Belo Horizonte. Anais X Reunião Científica ABRACE. Belo Horizonte: Escola de Belas Artes/UFMG, 2007. p. 1-4. Disponível em: www.portalabrace.org. Acesso em: 23 abr. 2021.

POLIGICCHIO, A. G. Teatro: materialização da narrativa matemática. 2011. Dissertação (Mestrado em Ensino de Ciências e Matemática) - Faculdade de Educação, Universidade de São Paulo, São Paulo, 2011.

POSSA, K; VARGAS, A. C. O desenho na Educação Infantil. Linguagem e expressão da subjetividade. E F Deportes.com, Revista Digital, Buenos Aires, n. 193, jun. 2014. Disponível em: https://www.efdeportes.com/efd193/desenho-na-educacao-infantil.htm. Acesso em: 23 abr. 2021.

ROQUE, T. História da matemática: uma visão crítica, desfazendo mitos e lendas. Rio de Janeiro: Zahar, 2013.

SÁ, I. P. de. Tendências Contemporâneas em Educação Matemática. 2016. Disponível em: http://www.magiadamatematica.com. Acesso em: 02 ago. 2020.

SANCHEZ, J. N. Garcia. Dificuldades de Aprendizagem e Intervenção Psicopedagógica. Porto Alegre: Artmed, 2004.

SANT'ANA, V. B. de. Teatro como prática para professores dos anos iniciais atuantes em Matemática, 2019. Dissertação (Mestrado em Ensino de Educação Básica) - Instituto de Aplicação Fernando Rodrigues da Silveira, Universidade do Estado do Rio de Janeiro, 2019.

SANT'ANA, V. B de; PORTO, M.B.D.da.S.M. Curso de Extensão: Dramatemática Sequência Didática, 2019a. Disponívelem: http:/leducapes.capes.gov.br/handle/capes/564444. Acesso em:02/08/2020.

Curso de Extensão Dramatemática, Diário: Aplicações e experiências aula a aula, 2019b. Disponível em: http://educapes.capes.gov.br/handle/capes/564445. Acesso em: 02/08//2020.

SPOLIN, V. Improvisação para o teatro. 4. ed. São Paulo: Perspectiva, 2005.

Jogos teatrais para a sala de aula: um manual para o professor. São Paulo: Perspectiva, 2008. 
225 Polyphonía, v. 32/2, jul./dez. 2021

SKOVSMOSE, O. Educação Matemática Crítica: a questão da democracia. São Paulo: Papirus, 2013.

VIGOTSKI, L. S. A Formação social da mente. 6. ed. São Paulo: Martins Fontes, 1998a.

VITTI, C. M. Matemática com prazer... A partir da História e da Geometria. Piracicaba: Unimep, 1995.

ZACARIAS, S. M. Z. A matemática e o fracasso escolar: medo, mito ou dificuldade, 2008. Dissertação (Mestrado em Educação) - Universidade do Oeste Paulista - UNOESTE: Presidente Prudente - SP, 2008.

Recebido em: 24 jan. 2021.

Aceito em: 28 abr. 2021. 